\title{
Determining methods of underwater visual census for estimating the abundance of coral reef fishes
}

\author{
Melita A. Samoilys ${ }^{\mathrm{a}} \&$ Gary Carlos ${ }^{\mathrm{b}}$ \\ Northern Fisheries Centre, Department of Primary Industries, Cairns, Queensland 4870, Australia \\ ${ }^{a}$ Current address: Fisheries, Department of Primary Industries, PO Box 1085, Townsville, \\ Queensland 4810, Australia (e-mail:samoilm@dpi.qld.gov.au) \\ ${ }^{\mathrm{b}}$ Current address: CRC Reef Research Centre, James Cook University, Townsville, \\ Queensland 4811, Australia
}

Received 20 October $1997 \quad$ Accepted 2 June 1999

Key words: tropical reef fish, Pacific fisheries, population assessment

\section{Synopsis}

We aimed to determine optimal methods of underwater visual census (UVC) for estimating the abundance of coral reef fishes exploited by fisheries in the tropical Pacific. Two main methods were tested using SCUBA: strip transect and stationary point counts. We assessed their relative accuracy, precision, power and efficiency (cost), and compared different census area dimensions, observer swimming speeds, and number of replicates. Twenty-five comparisons of the two UVC methods were conducted for 73 species from five families of coral reef fishes, on reefs in Australia and Fiji. Species were grouped within families based on their mobility. Few significant differences were found, either among or between strip transects and stationary point counts. The data were characterised by high variability, low precision and low power. A trend for greater accuracy in density estimates of small sedentary species with smaller census area was apparent, which probably reflects searching efficiency. Only one species group, the sedentary Acanthuridae showed differences between transects and point counts. Higher, hence presumably more accurate, density estimates were obtained with $50 \mathrm{~m} \times 5 \mathrm{~m}$ transects. Notably, point counts could be deployed in $\sim 70 \%$ of the time of transects. A bootstrapping procedure demonstrated a consistent improvement in precision of density estimates with increasing number of replicates, but no appreciable change in precision was found beyond 10 to 15 replicates, in all species groups and for both transects and point counts. Consequently, and because of the high variability inherent in fish density estimates, we recommend that at least 10 replicates be used to quantify the species considered here. The power calculations showed that only large differences in density will be detected with the replication levels typical of UVC surveys. Power was greatest for the roving serranids, with a decrease in density of about $50 \%$ detectable for this species group. We discuss the importance of carefully defining the behavioural attributes of species prior to selecting a UVC method. A method of temporal stratification in a count is described for censusing a range of species of varying mobilities. We suggest that fish mobility and search efficiency are key factors in optimising UVC methods.

\section{Introduction}

Underwater visual census (UVC) methods have been used extensively in reef fish studies of population dynamics, ecology and management (see reviews by Barans \& Bortone $^{1}$, Harmelin-Vivien et al. 1985,
${ }^{1}$ Barans, C.A. \& S.A. Bortone (ed.) 1983. The visual assessment of fish populations in the southeastern United States, 1982 Workshop. South Carolina Sea Grant Consortium, Tech. Rep. 1. $52 \mathrm{pp}$. 
Thresher \& Gunn 1986). Visual census methods can provide rapid estimates of relative abundance, biomass, and length frequency distributions of reef fish. For this reason, they have been used to census a wide range of demersal species that are taken by shallow water fisheries on coral reefs (Russ 1985, Kulbicki 1988, Samoilys 1988, McManus et al. 1992, Ayling \& Ayling 2 , Polunin \& Roberts 1993, Watson \& Ormond 1994, Jennings \& Polunin 1996).

In a fisheries context visual census estimates of fish abundance are particularly useful because they are independent of fishing methods. However, fisheries scientists have been reluctant to adopt the technique because of the lack of consensus on methodology by reef fish ecologists (Sale 1991). This lack of consensus relates to the inherent difficulty in censusing coral reef fishes. Coral reef fishes are speciose; exhibit various behavioural traits; have patchy distributions; occur in heterogeneous and diverse habitats; and occur in different geographic locations. These factors make it hard to determine optimal or standard survey methods. Nevertheless, visual census is the most practical method for monitoring the populations of coral reef fishes in shallow waters and therefore some standardisation of methods is urgently required.

This study focussed on a selection of species that are exploited in tropical Pacific fisheries. To establish some generalisations about UVC methods we examined the problems of counting reef fishes using a systematic combination of approaches to provide a unique and rigorous evaluation of the UVC method. Firstly, for our analyses, we divided the community of species into groups based on their mobility. Secondly, we compared two main methods (conducted on SCUBA): strip transect counts and stationary point counts, both of which are widely used (Sale \& Sharp 1983, Bohnsack \& Bannerot 1986, Thresher \& Gunn 1986) but, to our knowledge, have never been compared. Thirdly, we used three criteria to assess these methods: census area dimensions, observer swim speed, and replication. Fourthly, we tested the methods across a broad range of reefs.

To evaluate the two UVC methods (strip transects and point counts) we examined four factors: accuracy, precision, statistical power and efficiency (cost). Accuracy refers to how close a visual census estimate is to the

\footnotetext{
${ }^{2}$ Ayling, A.M. \& A.L. Ayling. 1986. A biological survey of selected reefs in the Capricorn section of the Great Barrier Reef Marine Park. Unpublished report for the Great Barrier Reef Marine Park Authority. 61pp.
}

true population mean; precision refers to the variability around the visual census estimate (which may or may not be accurate); power refers to the ability to detect differences between visual census estimates, which will depend on precision and statistical technique; and efficiency relates to how quickly a survey can be completed. Greater accuracy was assumed to be represented by the highest density of fish because visual counts invariably underestimate fish numbers (Sale \& Sharp 1983) and therefore the higher the mean estimate the closer it must be to the true mean (but see Samoilys \& Carlos $\left.{ }^{3}\right)$. This assumption is based on the principle that a human observer will always miss a small percentage of fish that are in the census area. High precision, represented by low variance, was sought because the lower the variability around the mean, the more powerful the method will be in detecting differences in abundance (Andrew \& Mapstone 1987), and the aim of visual surveys is invariably to detect differences between means (Samoilys 1997). Statistical power can be quantified (Zar 1996) and is clearly linked to variability. The time taken to do the census was used as a measure of its efficiency. Efficiency was given equal importance in our evaluation of the methods because every UVC sampling programme has budgetary constraints and therefore minimising field time is critical.

The three criteria selected to test the UVC methods: census dimensions, observer speed, and replication, were chosen because they are likely to have the greatest effect on census estimates (Sale \& Sharp 1983, Thresher \& Gunn 1986, Fowler 1987, Lincoln Smith 1988). The most appropriate area dimensions for a census will be a compromise between an observer's ability to count fish rapidly, and the behaviour, distribution and density of the fish. The smaller the census area the more thoroughly it can be searched, so narrow transects are likely to yield better counts. On the other hand, a narrow transect of practical length may be too small to yield adequate numbers for population assessment of the more mobile fish species typical of reef fisheries. This is because of the rates of movement and interaction with divers that occur with many of these species.

The speed of a census may bias visual estimates due to either the efficiency of the observer (Lincoln Smith 1988), or the presence of the diver (Thresher \& Gunn 1986, Fowler 1987). It is therefore preferable

\footnotetext{
${ }^{3}$ Samoilys, M.A. \& G. Carlos. 1992. Development of an underwater visual census method for assessing shallow water reef fish stocks in the south west Pacific. ACIAR Project PN8545 Final Report, April 1992. 100 pp.
} 
to determine optimal speed and then standardise it. In terms of cost, a rapid census is desirable, but clearly, if fish numbers are high and reef topography is complex, the observer will require a reasonable amount of time to search properly.

The number of replicates, or sample size, is an essential component of the experimental design of any visual census sampling programme. If the sample size is too small the power to detect differences among means is likely to be very low or inadequate, and if the sample size is too large effort is wasted (Bros \& Cowell 1987). The maximum number of replicates is based on factors such as time, money, materials and feasibility (Green 1979). The minimum number of replicates can be defined in terms of resolving power, i.e. the power to detect change in fish abundance.

To evaluate the criteria discussed above for two methods requires an enormous amount of field time. Therefore, to eliminate those techniques that showed little promise in terms of accuracy and precision, we first conducted a pilot study for initial trials among methods. Further comparisons of the more accurate and precise techniques were then made at several reefs in Australia and Fiji. The study is part of a project aimed at developing an effective technique for measuring stock density independently from fishery data for Pacific Island reef fisheries (Samoilys 1992, Samoilys \& Carlos ${ }^{3}$, Samoilys et al. ${ }^{4}$, Samoilys 1997).

\section{Methods}

\section{Study sites}

The pilot study was conducted in 1990 at Michaelmas Reef $\left(16^{\circ} 35^{\prime} \mathrm{S} 146^{\circ} 02^{\prime} \mathrm{E}\right)$, on the northern Great Barrier Reef. The main study was conducted at Michaelmas Reef, Scott Reef $\left(17^{\circ} 04^{\prime} \mathrm{S} 146^{\circ} 10^{\prime} \mathrm{E}\right)$ and Escape Reef $\left(15^{\circ} 52^{\prime} \mathrm{S} 145^{\circ} 48^{\prime} \mathrm{E}\right)$ on the Great Barrier Reef, and at Makogai Reef $\left(17^{\circ} 28^{\prime} \mathrm{S} 178^{\circ} 56^{\prime} \mathrm{E}\right)$ and Duff Reef $\left(16^{\circ} 48^{\prime} \mathrm{S} 178^{\circ} 58^{\prime} \mathrm{W}\right)$ in Fiji in $1990-1991$. To maximise the chances of high fish abundance and

\footnotetext{
${ }^{4}$ Samoilys, M., H. Fuentes, I. Tuwai, B. Tikomainiusiladi, J. Leqata, E. Oreihaka, A. Mobiha, T. Potuku, D. Die, S. Connell, M. Lincoln Smith, M. Wilson \& R. Watson. 1995. Application of underwater visual census to assessing coral reef fish stocks in the tropical Pacific. Report prepared for the Australian Centre for International Agricultural Research, ACIAR Project Number 9304, Final Report, September 1995. 225 pp.
}

species diversity, reefs that are closed to fishing or are lightly fished were selected. At the time of the study, Michaelmas and Escape reefs were zoned closed to fishing within the Great Barrier Reef Marine Park, and little fishing occured on the two Fijian reefs due to their remoteness.

All UVC counts were conducted on the leeward reef slopes, except at Michaelmas Reef (see main study below). Replicate visual census counts were placed within $1 \mathrm{~km}$ long sites. A practical method of measuring each site was developed: boat speed was calibrated against a fixed $100 \mathrm{~m}$ rope and each $1 \mathrm{~km}$ site was marked by buoys deployed during a timed run. The width of the site was determined by the angle of the slope. A depth of $15 \mathrm{~m}$ (due to decompression limitations of repetitive SCUBA diving) was set for the seaward boundary. On three of the reefs the leeward slopes were relatively steep, resulting in study sites of $20-50 \mathrm{~m}$ in width. The leeward slopes of the other two reefs (Michaelmas and Scott) were slight, thus the width of sites was fixed at $60 \mathrm{~m}$.

Replicate counts were positioned within sites by timed runs at positions chosen by a random number generator. Where a site was relatively wide, a similar method was used to locate the distance from the reef crest. Temporal deployment of the methods (the different transects and point counts, see below) was determined randomly to account for any variation introduced by the effects of tide and time of day.

\section{Species}

Species that are exploited in the commercial, artisanal, subsistence, and recreational coral reef fisheries of Fiji and Australia were selected. Those species that contribute the greatest weight to the fisheries in Fiji were chosen from catch records from the Fisheries Division of Fiji's Annual Reports. Species exploited in the Great Barrier Reef fisheries are predominantly the plectropomids (coral trout), lethrinids (emperors), and lutjanids (snapper) (Trainor 1991, Brown 1993, Kailola et al. 1993) which are also exploited in Fiji. Selection criteria also included suitability for visual census in terms of fish behaviour, habitat occurrence and crypticity. A list of 73 species from five families was composed (Table 1). In practice, the number of species encountered within any one census will only be in the order of 10-20. Every species in each family was recorded either by species name, or grouped in a genus or family group. Some species were grouped 
Table 1. Species checklist used in all UVC counts. Species groups (roving, small, etc.) based on fish mobility and/or size used in analyses of data are indicated. Asterisks indicate species which were grouped together for visual counting. The list was experimental, and not designed to be a standard checklist. NB. Certain species names have changed since checklist was designed.

\begin{tabular}{|c|c|}
\hline Scaridae & Acanthuridae \\
\hline Large & Sedentary \\
\hline Bolbometapon muricatum & Ctenochaetus striatus \\
\hline Cetoscarus bicolor & Acanthurus spp.* \\
\hline Hipposcarus longiceps & Ctenochaetus spp.* \\
\hline Scarus altipinnis & Zebrasoma spp.* \\
\hline S. frenatus & Naso vlamingii \\
\hline S. gibbus & Roving \\
\hline S. ghobban & A. dussumieri* \\
\hline \multirow[t]{2}{*}{ S. rubroviolaceus } & A. mata ${ }^{*}$ \\
\hline & A. xanthopterus* \\
\hline Small & A. lineatus \\
\hline Scarus niger & A. nigricauda \\
\hline \multirow[t]{2}{*}{$S$. spp. } & A. triostegus \\
\hline & N. annulatus \\
\hline Serranidae & N. brevirostris \\
\hline Sedentary & N. hexacanthus \\
\hline Aethaloperca rogaa & N. lituratus \\
\hline Anyperodon leucogrammicus & N. tuberosus \\
\hline Cephalopholis argus & N. unicornis \\
\hline C. cyanostigma & $N$. spp. \\
\hline \multicolumn{2}{|l|}{ C. miniatus } \\
\hline C. urodeta & Lutjanidae \\
\hline Cromileptes altivelis & Roving \\
\hline Epinephelus caeruleopunctatus & Aphareus furca \\
\hline E. fasciatus & Aprion viriscens \\
\hline E. maculatus & Lutjanus argentimaculatus \\
\hline E. merra & L. bohar \\
\hline E. microdon & L. carponotatus \\
\hline E. spp. & L. gibbus \\
\hline Large & L. rivulatus \\
\hline E. fuscoguttatus & L. sebae \\
\hline E. lanceolatus & Macolor spp. (2) \\
\hline E. malabaricus & Sedentary \\
\hline E. suillus & L. fulviflammus \\
\hline E. tauvina & L. fulvus \\
\hline E. tukula & L. kasmira \\
\hline Roving & L. monostigmus \\
\hline Plectropomus areolatus & L. quinquelineatus \\
\hline P. laevis & L. vittus \\
\hline \multirow{2}{*}{\multicolumn{2}{|c|}{ P. maculatus }} \\
\hline & \\
\hline \multicolumn{2}{|l|}{ Variola spp. (2) } \\
\hline \multicolumn{2}{|l|}{ Lethrinidae } \\
\hline \multicolumn{2}{|l|}{ Gymnocranius spp. } \\
\hline \multicolumn{2}{|l|}{ Lethrinus elongatus } \\
\hline \multicolumn{2}{|l|}{ L. harak } \\
\hline \multicolumn{2}{|l|}{ L. kallopterus } \\
\hline \multicolumn{2}{|l|}{ L. mahsena } \\
\hline \multicolumn{2}{|l|}{ L. miniatus } \\
\hline \multicolumn{2}{|l|}{ L. nebulosus } \\
\hline \multicolumn{2}{|l|}{ L. ornatus } \\
\hline \multicolumn{2}{|l|}{ L. ramak } \\
\hline \multicolumn{2}{|l|}{ L. rubrioperculatus ${ }^{*}$} \\
\hline \multicolumn{2}{|l|}{ L. variegatus* } \\
\hline \multicolumn{2}{|l|}{ L. semicinctus* } \\
\hline \multicolumn{2}{|l|}{ L. xanthochilus } \\
\hline$L$. spp. & \\
\hline Monotaxis grandoculis & \\
\hline
\end{tabular}


together because they are difficult to identify underwater. Observers were trained in species identification, aided by the maintenance of frozen reference samples in the laboratory and a large number of reference sources (Carcasson 1977, Grant 1982, Randall 1983, Randall \& Ben-Tuvia 1983, Fischer \& Bianchi 1984, Masuda et al. 1984, Allen 1985, 1987, Choat \& Randall 1986, Randall \& Hoese 1986, Smith \& Heemstra 1986, Randall 1987, Allen \& Swainston 1988, Carpenter \& Allen 1989, Myers 1989).

The mobility of fish relative to the census area is likely to have the greatest impact on the accuracy of the visual census method. Therefore the species list was divided into species groups based on their mobility (Table 1). Primarily, species in each family were grouped as either 'sedentary' or 'roving', a priori, based on our observations of the species' behaviour. Scaridae are, in general, all highly mobile in their behaviour, and therefore this family was grouped by size: 'small' and 'large'. The small scarids, though mobile, are more likely to remain within a limited area during the census period because of their size; the converse is true of the large scarids. The lethrinids are all roving in their behaviour and were therefore not subdivided. The serranids were divided into three groups: the small or cryptic 'sedentary' species, and the 'large' but cryptic species and the 'roving' non-cryptic plectropomids and Variola spp.

\section{UVC methods}

To minimise error and keep any bias constant, the procedures for deploying visual counts (all methods) were standardised wherever possible. For example, one observer (MS) was used throughout the pilot study to eliminate any bias due to differences between observers. In the main study, census counts were split between the two trained observers (MS \& GC) having first determined there was no significant difference $(p>0.05)$ in the estimates of fish density obtained by these two observers (using paired t-tests at 6 sites, with $\mathrm{n}=8$ for each observer, Samoilys $\&$ Carlos $\left.^{3}\right)$. All species were recorded in the same count (cf. Lincoln Smith 1989), on the assumption that there was no interaction between method (point or transect, census dimension, speed, etc.) and counting all species simultaneously. The minimum size of fish counted was fixed at $11 \mathrm{~cm}$ FL. It is difficult for an observer to try and estimate visually a wide range of sizes of fish (Bellwood \& Alcala 1988), particularly the very small sizes. A minimum size of $11 \mathrm{~cm}$ FL was considered practical visually and biologically in terms of the species being censused and their size ranges. For many of the species this minimum size included juveniles.

Fish densities refer to the number of fish occupying the census area. Fish that entered the area after the count started were not counted (Samoilys \& Carlos $^{3}$ ). In all comparisons of methods, the order in which the methods were deployed was randomised in each study site.

\section{Transect method}

The transect method counted fishes within a rectangular strip of reef. To avoid the localised disturbance that may have resulted from anchoring the boat and from divers entering the water, the two observers swam for a set number of fin beats along the reef before starting the count. Observer One recorded the fish while Observer Two laid out the fibreglass tape-measure and maintained a constant speed and the direction of the transect. The count began as soon as Observer Two had tied the end of the tape measure to the bottom and started the stop-watch. A fixed length of $3 \mathrm{~mm}$ floating rope, maintained above the coral by an attached fishing float, was tied between the two observers to mark the transect width. Start and stop signals between the observers were established prior to counting. Observer One recorded all numbers of fish included on the species checklist. Counting was temporally stratified to 'capture' those fish most likely to leave the area because of the approach of a diver. Thus, the larger more mobile species were counted first (e.g. Lethrinidae), and the smaller less mobile species (e.g. sedentary Acanthuridae) were counted later.

Mapstone \& Ayling 5 found that very short (25 m), very long $(100 \mathrm{~m})$, and very wide $(20 \mathrm{~m})$ transects were unsuitable for several species considered in the present study, so we selected mid-range transect sizes for this study, i.e. 50 and $75 \mathrm{~m}$ lengths, and $10 \mathrm{~m}$ and $5 \mathrm{~m}$ widths.

\section{Point count method}

The stationary point count method recorded fish within a circular area. The method required only one observer (one diver in the water). This was acceptable within the

\footnotetext{
${ }^{5}$ Mapstone, B.D. \& A.M. Ayling. 1993. An investigation of optimum methods and unit sizes for the visual estimation of abundances of some coral reef organisms. A Report to the Great Barrier Reef Marine Park Authority. 71 pp.
} 
SCUBA diving regulations at the time of the study. The method can also be conducted with two divers. As for transect counts, the observer swam a set number of fin beats away from the boat before starting the count, but in this case on the surface. The observer then descended and as soon as the reef was visible, started the stop watch and began counting the fish. The observer visually fixed a central point on the bottom to mark the centre of the stationary point count, while simultaneously estimating the radius of the count area-e.g $10 \mathrm{~m}$ from the central point, noting features of the substratum to mark the circular boundary of the census. As in the transect method, the larger more mobile species were counted first and the smaller less mobile species were counted later. Counting continued for a fixed time (e.g. $10 \mathrm{~min}$ ) and all fish seen within the boundaries were recorded. After the count the observer measured two radius estimates of the count area by laying the fibreglass tape-measure between two boundary landmarks and across the centre-point. Thus an actual measure of the area of the count could be calculated.

The radius was standardised at $10 \mathrm{~m}$ to encompass a large enough sample area for the types of species being censused, while still maintaining the boundaries within the range of visibility. This was an expansion of Bohnsack \& Bannerot's (1986) 7.5 m radius point count used to sample a range of reef fish including very small species. It was necessary that the entire count area was visible from its centre so that the observer can rapidly fix the boundary positions. After the boundaries are known and the mobile species have been recorded, the entire area can then be searched in more detail for cryptic fish.

Pilot study - The pilot study was conducted on the leeward slope of Michaelmas Reef for consistency and because it is protected from the prevailing winds and can therefore be worked in most weather conditions.

To select methods for the pilot study, census speed $\left(\right.$ Fast $=75 \mathrm{~m}^{2} \mathrm{~min}^{-1}$, Medium $=50 \mathrm{~m}^{2} \mathrm{~min}^{-1}$, Slow $=33 \mathrm{~m}^{2} \mathrm{~min}^{-1}$ ) was first compared for each of two transect dimensions: $75 \mathrm{~m} \times 10 \mathrm{~m}$ and $75 \mathrm{~m} \times 5 \mathrm{~m}$, with a replication level of 4 for each method, repeated in two replicate study sites. Only one transect length (75 m) was used for the speed trials on the assumption that there would be no interaction between transect length and speed. Transect width and census duration are more likely to affect an observer's ability to count fish than is transect length. Transect length is more likely to be related to the adequacy of the sampling area with respect to the distribution of the fish (density, contagion, etc.), and is unlikely to interact with width or speed. Three factor ANOVAs (site, transect width, and speed) run on each species group (Table 1) separately did not detect any significant differences $(p>0.05)$ in density between the 6 methods. There was a trend for higher mean densities with the slow $5 \mathrm{~m}$ width transects, therefore fast transects and most wide $(10 \mathrm{~m})$ transect dimensions were not tested further. The subsequent methods selected and the design of the comparisons for the pilot study are shown in Table 2 . The replication level of 11 for point counts was based on an equivalent effort in terms of field time to 8 transects (see 'efficiency' below). This decision was based on one of our four prime objectives: to determine an efficient method for assessing fish population densities. We therefore elected to use field time to define the two methods. The pilot study was conducted in one site only due to time constraints.

Main study - Based on the results of the pilot study (see Results) the main study compared the 10 m radius point count and the slow $\left(33 \mathrm{~m}^{2} \mathrm{~min}^{-1}\right) 50 \times 5 \mathrm{~m}$ transect at eight locations across five reefs (Table 3 ). The minimum number of replicates required for each method was determined by conducting the maximum number of replicates logistically feasible (16 transects and 30 point counts in one study site on the leeward slope of Michaelmas Reef), and examining the coefficient of variation by bootstrapping (see Data analyses). Replication levels were subsequently set at 10 transects and 14 point counts, based on an equivalent effort in terms of field time. This ensured the time taken to complete

Table 2. Methods and sampling design for the pilot study at Michaelmas Reef. Observer speed or count rates: Slow $=33 \mathrm{~m}^{2} \mathrm{~min}^{-1}$; Medium $=50 \mathrm{~m}^{2} \mathrm{~min}^{-1}$. Note the equivalent speed for the stationary point count is $49 \mathrm{~m}^{2} \mathrm{~min}^{-1} .50 \times 5 \mathrm{~m}$, etc. $=$ transects, $10 \mathrm{~m}$ radius $=$ point counts

\begin{tabular}{llllll}
\hline Method & $50 \times 5 \mathrm{~m}$ & $75 \times 5 \mathrm{~m}$ & $75 \times 5 \mathrm{~m}$ & $75 \times 10 \mathrm{~m}$ & $10 \mathrm{~m}$ radius \\
\hline Speed/time & Slow & Slow & Medium & Medium & $7 \mathrm{~min}$ \\
Replicates & 8 & 8 & 8 & 8 & 11 \\
\hline
\end{tabular}


Table 3. Sampling design for comparison of $10 \mathrm{~m}$ radius point counts and $50 \times 5 \mathrm{~m}$ transects on three reefs in Australia and two reefs in Fiji.

\begin{tabular}{lll}
\hline Reef & Site A & Site B \\
\hline Scott & 9 Transects & - \\
(Australia) & 12 Points & - \\
Michaelmas & 10 Transects & 10 Transects \\
(Australia) & 14 Points & 14 Points \\
Escape & 10 Transects & 10 Transects \\
(Australia) & 14 Points & 14 Points \\
Makogai & 10 Transects & 10 Transects \\
(Fiji) & 14 Points & 14 Points \\
Duff & 8 Transects & - \\
(Fiji) & 11 points & - \\
\hline
\end{tabular}

surveys or method efficiency (cost) was factored into the comparisons.

Study sites were selected on the leeward faces of reefs to standardise on effects of wind exposure, with the exception of Michaelmas Reef which has a well formed reef slope only on the windward face. The missing replicate study sites and replicates at Scott and Duff reefs (Table 3), were due to logistic difficulties in the field.

Different dimensions of point counts were also examined because the less visible species may be incompletely sampled by a large $(10 \mathrm{~m}$ radius $)$ point count. Estimates of fish density obtained from 'standard' $10 \mathrm{~m}$ radius point counts were compared with density estimates from $7 \mathrm{~m}$ and $5 \mathrm{~m}$ radius point counts at Duff Reef in Fiji.

The time taken to complete field surveys for slow $75 \times 5 \mathrm{~m}$ strip transects and $7 \mathrm{~min} 10 \mathrm{~m}$ radius stationary point counts was recorded at Makogai Reef (Fiji) and Michaelmas Reef (Australia) to assess the relative efficiency of the two methods. The time taken to complete one count was taken as the time from the start of the count to the start of the next count, i.e. boat time was included.

\section{Data analyses}

\section{Replication}

The best available estimate of population variance was obtained from the large number of replicates (16 transects and 30 point counts) from Michaelmas Reef. The minimum acceptable sample size (replication level) was defined by plotting the variability of the data as a function of number of replicates for each method. A bootstrapping procedure (Efron \& Tibshirani 1993) was applied to randomly select from the 'population' of density counts 1000 estimates of mean density for every level of replication (two to 16 from the transect series and two to 30 from the point count series). The coefficient of variation (standard deviation/mean) for each set of 1000 density estimates was plotted as a function of replication to examine changes in variability of the estimates with different sampling effort.

\section{Accuracy}

Having first tested for normality and homogeneity of variances, analyses of variance (ANOVA, Zar 1996, Winer et al. 1991, Underwood 1981) was used to test for differences between mean density estimates $\left(\log _{10}(\mathrm{x}+1)\right.$ transformed $)$ from the different UVC methods. Three factor and single factor ANOVAs were used in the pilot study. For the main study a 2-way mixed ANOVA model was used to test the null hypothesis that there were no differences in the density estimates obtained by the two methods, i.e. the methods were similar in their accuracy. Due to the nonorthogonal design of the data matrix (Table 3), the model was based on eight separate locations rather than sites nested within reefs. (The second hypothesis tested by the model but not of relevance here, was that the variation among locations was the same as the variation within locations.)

\section{Precision}

Standard error (of the mean) to mean ratios (SE: $\bar{x}$ ) are often calculated to examine precision of data in marine ecology (Thresher \& Gunn 1986, Andrew \& Mapstone 1987). However, the SE : mean ratio is a relative measure because it sets precision as a percentage of the mean; SE is the usual measure of precision. With non-normal distributions of data, as is the case when sampling most animal populations, the variance and mean tend to increase together. Taylor's power law $\left(\mathrm{S}^{2}=\mathrm{a} \cdot \bar{x}^{\mathrm{b}}\right.$, Southwood 1978) describes this relationship, where the constant $b$, describes the degree of contagion. Only with moderately contagious distributions $(b=2)$ will the $S E$ : mean ratio be independent of the mean, and therefore provide an independent measure of precision. Calculations of $b$ gave values greater than 2 for all datasets and therefore we chose not to use $\mathrm{SE}$ : mean ratios as an index of precision; instead, we used standard errors. 


\section{Power}

The minimum detectable difference was calculated using $\log _{10}(\mathrm{x}+1)$ transformed data from the following formula (Zar 1996), where power was specified as $90 \%$ $(\beta=0.1)$, at a $5 \%$ level of significance $(\alpha=0.05)$.

$$
\delta=\sqrt{\frac{2 \mathrm{ks}^{2} \Phi^{2}}{\mathrm{nl}}},
$$

where $\delta=$ detectable difference, $\phi$ is the test statistic; $\mathrm{n}=$ replicate number; $\mathrm{k}=$ number of groups (populations); $s^{2}=$ variance. Each calculation refers to the minimum detectable difference on a log scale. On the original scale, this is interpreted as a proportion of the mean.

\section{Efficiency}

A simple comparison of mean times taken to conduct transect and point counts, and the calculation of point count : transect count time ratios was used to compare the efficiency of the two methods.

\section{Results}

Pilot study

No significant differences were detected between the five UVC methods tested in the pilot study: $50 \times 5 \mathrm{~m}$ (slow), $75 \times 5 \mathrm{~m}$ (slow \& medium), $75 \times 10 \mathrm{~m}$ (medium) transects and $10 \mathrm{~m}$ point counts, for any of the species groups (Figure 1, Table 4). The leeward slope of Michaelmas Reef was patchy and heterogeneous in habitat which may partly explain the high variation making detection of differences difficult. However, there was a trend for the point counts and the $50 \mathrm{~m} \times 5 \mathrm{~m}$ transects to give higher abundances for most species groups. For the Lutjanidae densities of fish were so low, and variances so high, that little can be inferred from the results. In comparing the $50 \mathrm{~m} \times 5 \mathrm{~m}$ and the $75 \mathrm{~m} \times 5 \mathrm{~m}$ transects of the same (slow) speed, the $50 \mathrm{~m}$ long transects recorded greater densities (though not statistically significant) than the $75 \mathrm{~m}$ transects for all species groups except the small serranids. In the
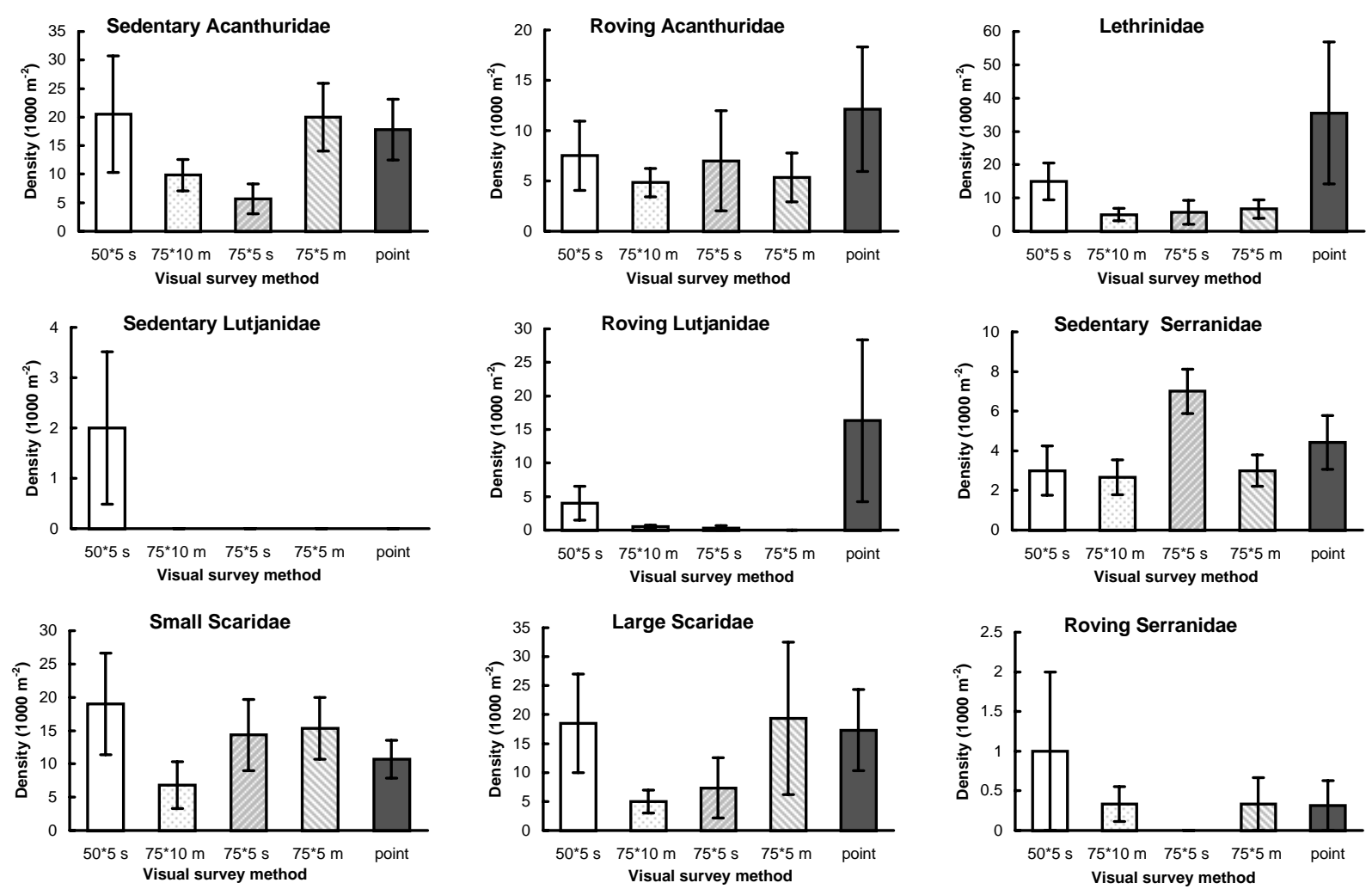

Figure 1. Mean density of fish estimated by 5 UVC methods at one site on the leeward slope of Michaelmas Reef, Great Barrier Reef. Error bars represent standard errors. $50 \times 5$ etc. $=$ strip transect dimensions in metres. $\mathrm{s}=\mathrm{slow}, 33 \mathrm{~m}^{2} \mathrm{~min}^{-1} ; \mathrm{m}=$ medium, $50 \mathrm{~m}^{2} \mathrm{~min}^{-1}$; point $=10 \mathrm{~m}$ radius stationary point count. $\mathrm{n}=8$ (transects) or 11 (points). Species groups are described in Table 1 . 
Table 4. Summary of single factor ANOVAs comparing 5 UVC methods for each species group, tested in the pilot study (Table 2) on the leeward slope of Michaelmas Reef. The large serranids are not shown because only one individual was recorded throughout the survey. Species groups are described in Table 1.

\begin{tabular}{llll}
\hline Species groups & d.f. & F ratio & Probability \\
\hline Sedentary Acanthuridae & 4,38 & 1.81 & 0.148 \\
Roving Acanthuridae & 4,38 & 0.68 & 0.609 \\
Lethrinidae & 4,38 & 1.03 & 0.403 \\
Roving Lutjanidae & 4,38 & 0.79 & 0.537 \\
Sedentary Lutjanidae & 4,38 & 1.09 & 0.375 \\
Large Scaridae & 4,38 & 0.92 & 0.462 \\
Small Scaridae & 4,38 & 0.59 & 0.669 \\
Small Serranidae & 4,38 & 2.24 & 0.082 \\
Roving Serranidae & 4,38 & 0.77 & 0.554 \\
\hline
\end{tabular}

latter species group the $75 \mathrm{~m}$ long transect recorded the highest mean density compared with all other methods. Precision in the estimates of abundance, illustrated by the standard errors, was generally low and showed little improvement with any of the methods across all species groups. Since there were no significant differences, the selection of $50 \times 5 \mathrm{~m}$ transects for the main study was based on the trend for higher densities with this dimension.

\section{Main study}

\section{Replication}

The number of replicates at which the rate of reduction in coefficient of variation is sharply reduced can be used to determine the minimum acceptable replication level (Bros \& Cowell 1987). In other words, increasing replication beyond this level will not appreciably reduce variability in the data. The bootstrapping analysis suggested that a minimum of 10-15 replicates for both methods for all species groups was appropriate (Figure 2). There was no discernible difference in the rate of reduction in coefficient of variation with level of replication between the point counts and transects. The magnitude of variability in the estimates for most of the larger, more mobile species groups surveyed was either similar between methods, or lower for the point count method. The point counts also returned a lower variability for the smaller species groups (sedentary Acanthuridae and small Scaridae), but registered a higher variability for the Lethrinidae and small Serranidae.

\section{Comparison of strip transects and} stationary point counts

For all but one species group there was no significant difference $(\mathrm{p}>0.05)$ in the density estimate obtained by the $50 \mathrm{~m} \times 5 \mathrm{~m}$ transect method and the $10 \mathrm{~m}$ radius point count method (Figure 3, Table 5). For the sedentary Acanthuridae the transect method gave significantly higher $(\mathrm{p}<0.05)$ density estimates. Precision in the estimates of abundance, demonstrated by standard errors, was generally low. There was a tendency for precision to be greater with point counts, across most species groups.

Power

The minimum detectable difference, calculated on a $\log$ scale for a power of $90 \%$, was smaller for the point counts compared with the transects for every species group except for the roving serranids (Table 6). For both methods and for all species groups, except the roving serranids, power was low. For example to detect a decrease in density, numbers of fish would need to drop to between $21 \%$ and $49 \%$ of the original mean as measured by point counts, and to between $9 \%$ and $54 \%$ of the original mean for transects. Power was greatest for the roving serranids with a decrease in density of around $50 \%$ of the mean being detectable.

\section{Efficiency}

The point counts were quicker to deploy than the $75 \times 5 \mathrm{~m}$ transects (Table 7). The ratio of point count to transect count time was 0.6 at both Makogai and Michaelmas reefs. Based on the slow census speed and an average swimming speed, derived times for $50 \mathrm{~m}$ transects gave a ratio of around 0.7 .

\section{Point count dimensions}

Species groups responded in different ways to changes in point count radius (Figure 4). Variation was generally very high, but the following trends were apparent: there was little difference in density estimates with changes in point count dimensions for both large and small Scaridae, and the Lethrinidae. In contrast, the sedentary Acanthuridae, roving Lutjanidae, and sedentary Serranidae densities were higher in the smaller point counts. Insufficient data and high variability prevented any assessment of the roving Serranidae and sedentary Lutjanidae. 

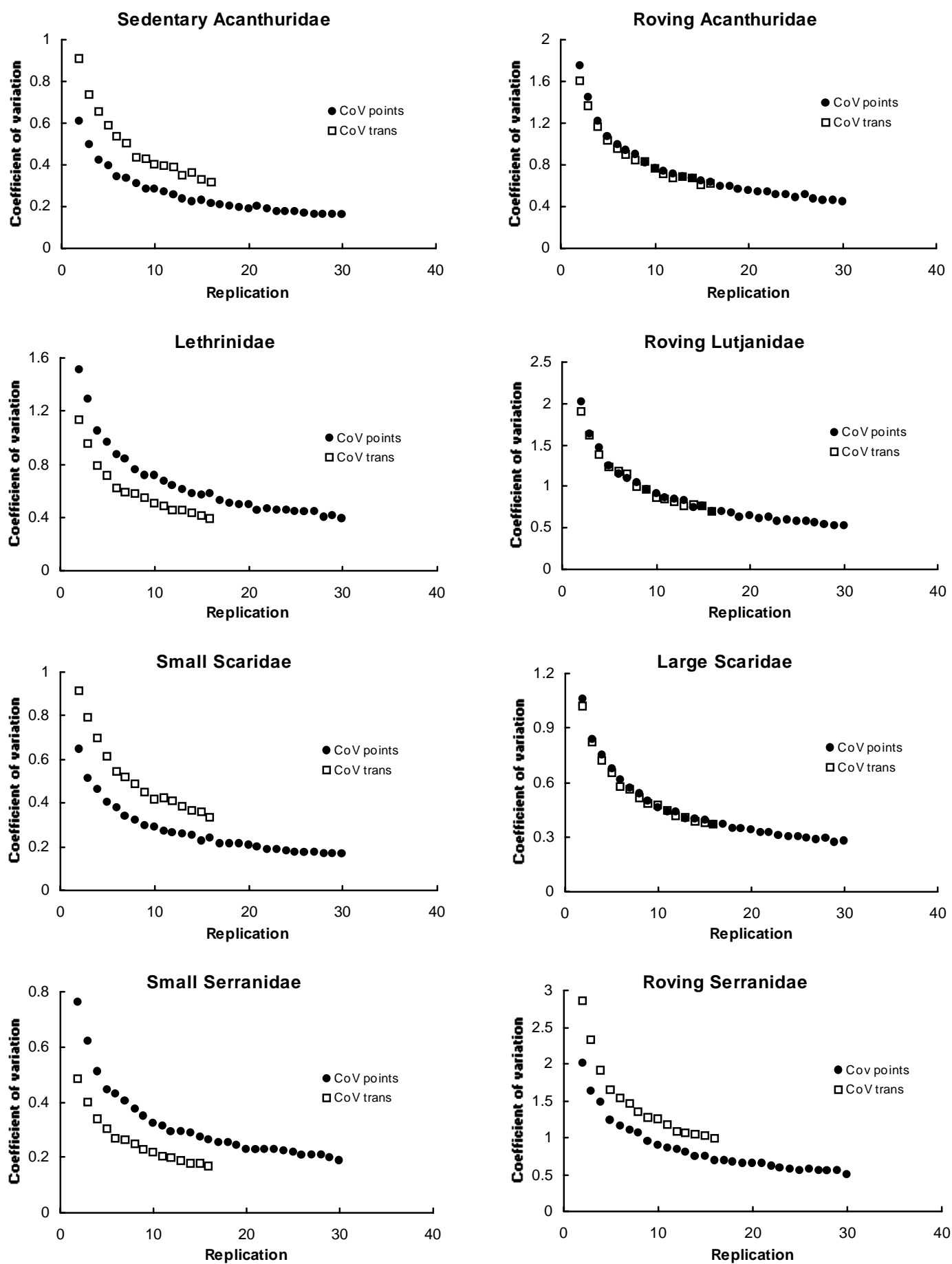

Figure 2. Change in variability of estimates of mean density with increasing replication level derived by bootstrapping from $10 \mathrm{~m}$ radius point counts (points) and slow $50 \mathrm{~m} \times 5 \mathrm{~m}$ transects (trans) on the leeward slope of Michaelmas Reef. Sedentary Lutjanidae and large Serranidae have been omitted due to lack of sightings. $\mathrm{CoV}=$ coefficient of variation. 

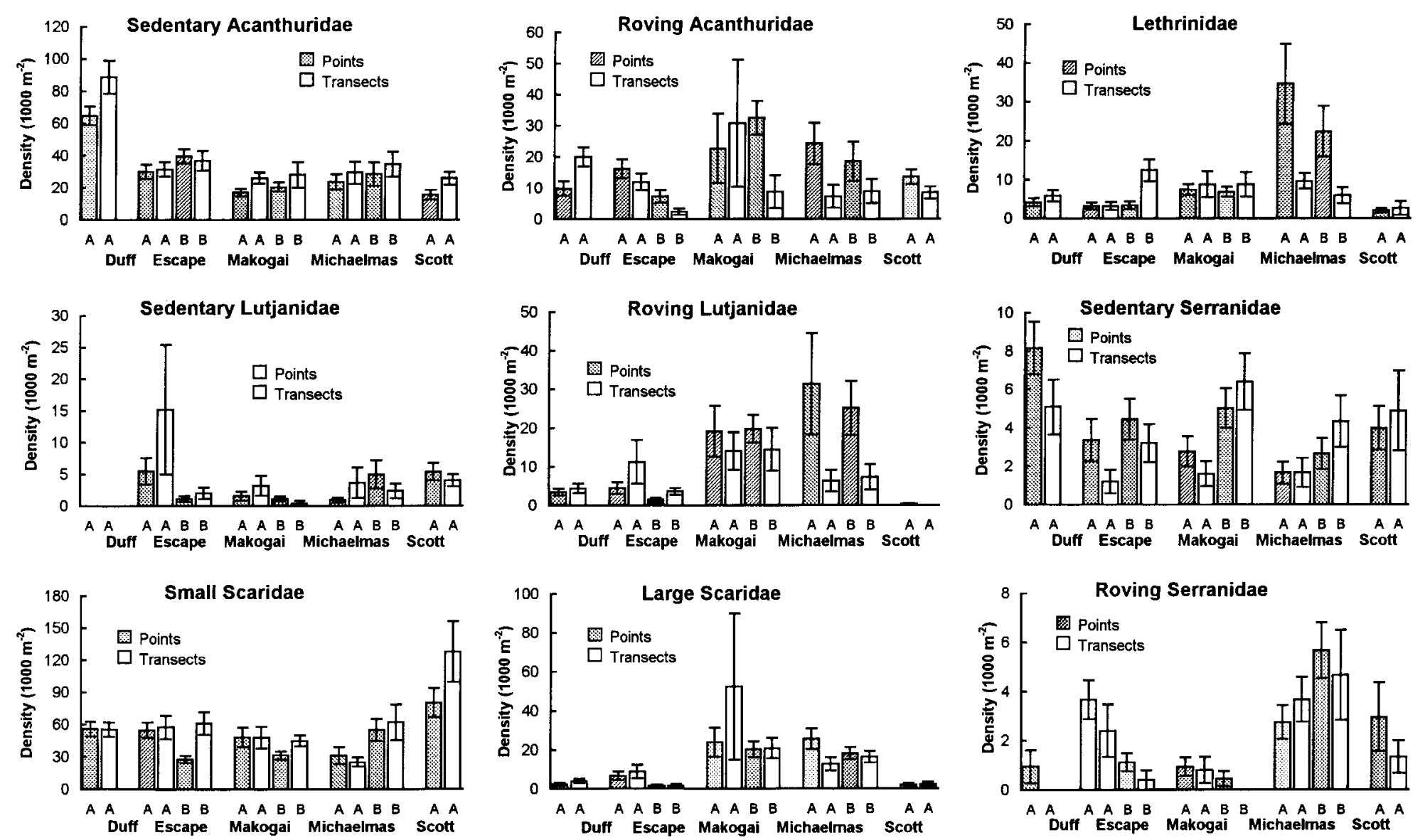

Figure 3. Mean density of fish estimated by $10 \mathrm{~m}$ radius point counts and $50 \mathrm{~m} \times 5 \mathrm{~m}$ transects at five reefs in Australia and Fiji. Error bars represent standard errors. Species groups are described in Table 1, replication levels are given in Table 3. A, B = study sites. 


\section{Discussion}

Most studies that have employed underwater visual census methods for estimating fish abundance have not had the luxury of conducting an extensive pilot study. Choosing the most appropriate method is usually based on the researcher's experience, commonsense, personal bias and previously used methods. This study aimed to quantify differences between various UVC methods to provide some guidelines on selecting the optimal method for a particular sampling programme. We conducted 25 comparisons of different UVC methods, but found few significant differences either among or between the strip transects and stationary point counts.

Table 5. Summary of mixed model ANOVAs comparing $10 \mathrm{~m}$ radius point counts and $50 \times 5 \mathrm{~m}$ transects for each species group, at eight locations on reefs in Australia and Fiji. F ratios represent MS (method)/MS (method $\times$ location).

\begin{tabular}{lccl}
\hline Species group & d.f. & F ratio & Probability \\
\hline Roving Acanthuridae & 1,7 & 4.256 & 0.078 \\
Sedentary Acanthuridae & 1,7 & 8.929 & 0.020 \\
Lethrinidae & 1,7 & 0.131 & 0.728 \\
Roving Lutjanidae & 1,7 & 1.080 & 0.333 \\
Sedentary Lutjanidae & 1,7 & 3.596 & 0.100 \\
Large Scaridae & 1,7 & 0.046 & 0.837 \\
Small Scaridae & 1,7 & 0.595 & 0.466 \\
Roving Serranidae & 1,7 & 4.863 & 0.063 \\
Sedentary Serranidae & 1,7 & 0.108 & 0.752 \\
\hline
\end{tabular}

In assessing the relative accuracy of various UVC methods we assumed that higher estimates of density implied greater accuracy (Sale \& Sharp 1983). Although the potential to overestimate abundance with UVC surveys has been demonstrated (Samoilys \& Carlos ${ }^{3}$, Watson et al. 1995) overall, UVC counts generally underestimate abundance (Brock 1982, Sale \& Sharp 1983, Sale 1991, Samoilys \& Carlos $^{3}$ ). The apparent trend of lower density estimates with wider and faster strip transects probably related to search times, with lower estimates of abundance reflecting a low counting efficiency resulting from lack of time to thoroughly search the census area. We therefore recommend slow $\left(33 \mathrm{~m}^{2} \mathrm{~min}^{-1}\right) 50 \mathrm{~m} \times 5 \mathrm{~m}$ transects, a similar conclusion drawn by Mapstone \& Ayling 5 . The reduction in stationary point count radius from $10 \mathrm{~m}$ to $7 \mathrm{~m}$ or $5 \mathrm{~m}$ resulted in an increase in the estimates of density for some species groups, and had no effect for other species groups. The response appeared to be related to sightability of fish. Similar density estimates were obtained for the Scaridae and Lethrinidae which are visually conspicuous mobile fishes and therefore relatively easy to sight. However, for the sedentary Acanthuridae and sedentary Serranidae, estimates of density were higher in the smaller point counts. These species groups are more associated with the substrate and are generally less conspicuous. This suggests that a $10 \mathrm{~m}$ radius point count is too large for an observer to search effectively for these species, especially when simultaneously counting other species. Thus smaller point counts are recommended for these

Table 6. Minimum detectable differences from circular point counts $(\mathrm{n}=$ $18)$ and $50 \mathrm{~m} \times 5 \mathrm{~m}$ transects $(\mathrm{n}=10)$ at Makogai Reef, Fiji. $\delta=$ minimum detectable difference on a $\log$ scale where $\alpha=0.5, \beta=0.10$ (i.e. power $=$ $90 \%)$. This translates to a proportion of the mean on the original scale. An example is given in the $\%$ of mean values which relate to how low the density (as a $\%$ of the mean) would have to drop before the change was detected.

\begin{tabular}{lllllr}
\hline Species group & \multicolumn{2}{l}{$\delta(\log$ scale $)$} & & $\%$ of mean (original scale) \\
\cline { 2 - 3 } \cline { 5 - 6 } \cline { 5 - 6 } $\begin{array}{lllll}\text { Point } \\
\text { counts }\end{array}$ & Transects & & $\begin{array}{l}\text { Point } \\
\text { counts }\end{array}$ & Transects \\
\hline Roving lutjanids & 0.647 & 0.816 & & 22.5 & 15.3 \\
Sedentary lutjanids & 0.385 & 0.575 & & 41.2 & 26.5 \\
Large scarids & 0.678 & 1.058 & & 21.0 & 8.8 \\
Small scarids & 0.408 & 0.624 & & 39.0 & 23.8 \\
Lethrinids & 0.527 & 0.704 & & 29.7 & 19.8 \\
Roving serranids & 0.309 & 0.269 & & 49.1 & 53.8 \\
\hline
\end{tabular}


species groups. Given these species specific results, a compromise of $7 \mathrm{~m}$ radius would be the most appropriate point count dimension for counting a range of species simultaneously, similar to the $7.5 \mathrm{~m}$ radius developed by Bohnsack \& Bannerot (1986).

Table 7. Efficiency calculations for transects (slow $75 \times 5 \mathrm{~m}$ ) and point counts ( $7 \mathrm{~min} 10 \mathrm{~m}$ radius) at two reefs. Times are averages for the completion of one count including preparations for the next one (eg. boat travel and anchoring). Times in parentheses are estimations for $50 \times 5 \mathrm{~m}$ transects derived from the $75 \mathrm{~m}$ transects data. $\mathrm{SD}=$ standard deviation.

\begin{tabular}{lcclll}
\hline & \multicolumn{2}{l}{ Makogai, Fiji } & & \multicolumn{2}{c}{ Michaelmas, Australia } \\
\cline { 2 - 3 } \cline { 5 - 6 } & Point & Transect & & Point & Transect \\
\hline Time (min) & 26.0 & $43.5(38.1)$ & & 19.7 & $32.5(27.0)$ \\
SD & 6.4 & 9.5 & & 6.0 & 4.6 \\
$\mathrm{n}$ & 36 & 20 & & 29 & 18 \\
\hline
\end{tabular}

Despite clear demonstrations that transect census speed affects density estimates (Lincoln Smith 1988, Watson et al. 1995), and this effect varies with different types of fish, reef fish ecologists still tend to overlook this factor. Our results support Lincoln Smith's (1988) recommendation for slow speeds to improve searching efficiency, and the need to standardise. The concern that standardising speed may increase errors in overcounting the more mobile species (Lincoln Smith 1988, Samoilys 1992) is valid. Transect speed should be as rapid as possible without compromising search efficiency, and observers must be trained not to count individuals that enter the census area after the census has started (Samoilys \& Carlos $^{3}$, Watson et al. 1995).

In testing the $50 \mathrm{~m} \times 5 \mathrm{~m}$ transects and $10 \mathrm{~m}$ radius point counts on a range of reefs in Australia and Fiji we found the only differences detected were for the sedentary Acanthuridae, with higher densities recorded by
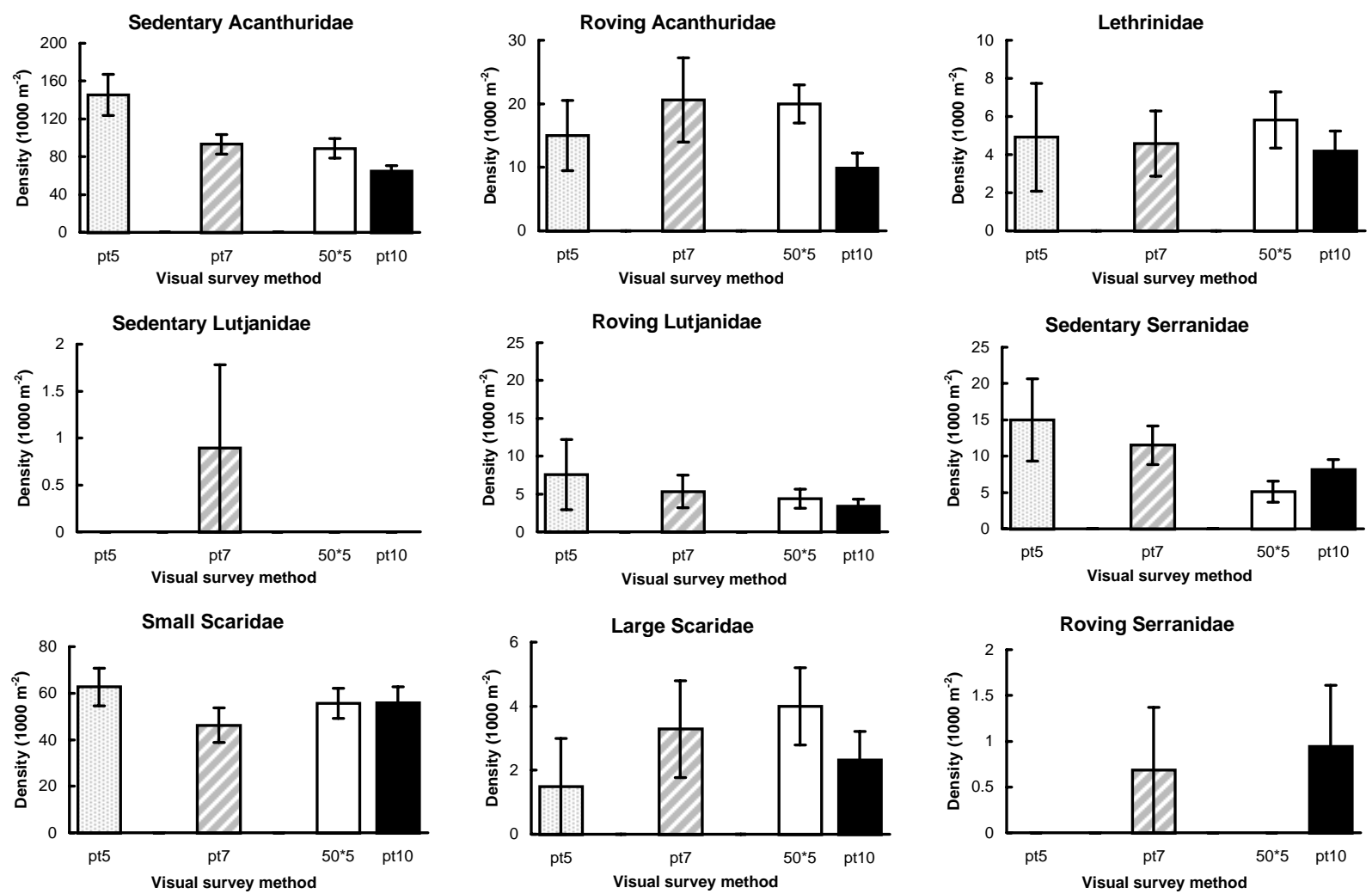

Figure 4. Changes in abundance of fishes with point count radius for the different species groups at Duff Reef, Fiji. $50 \mathrm{~m} \times 5 \mathrm{~m}$ transects are also shown. Error bars represent standard errors. pt5 etc. $=5$ metre radius point count. $\mathrm{n}=11(\mathrm{pt} 5, \mathrm{pt} 7,50 * 5), \mathrm{n}=12(\mathrm{pt} 10)$. Placement of bars along axis is in approximate proportion to count area 
transects. However, numbers of sedentary Lutjanidae and large Serranidae were very low, and therefore no conclusions could be drawn about these species groups. These results were consistent on reefs in Australia and Fiji. Again, this finding is likely to be related to search efficiency since sedentary acanthurids are less conspicuous and require careful searching. This is possibly easier in a $50 \mathrm{~m} \times 5 \mathrm{~m}$ transect compared with a large (10 $\mathrm{m}$ radius) point count.

There is clearly potential for error in the visual estimation of the circular boundary of a point count, and since area is proportional to the square of the radius, any error in distance estimation will be squared. It is therefore recommended that 2 radii are measured to provide a more accurate estimate of the actual area censused (e.g. present study; Jennings \& Polunin 1996, Jennings et al. 1996). This also provides a check on the observer's accuracy through time. It has been demonstrated that trained observers need continuous re-training in length estimation of fishes (Bell et al. 1985, Samoilys 1997), which is also likely to be the case for radius estimation. Strip transects are also subject to boundary estimation error. First, observers have to visually estimate the transect boundaries ahead, and in many cases researchers do not measure the width (e.g. English et al. 1994). Thus errors in area estimates are directly proportional to errors in width estimation. The use of a rope of fixed length between observers when using transects is easy and is recommended for this method to reduce errors in area estimation.

The results from the bootstrapping analysis of the data from the replication series showed, not unexpectedly, a consistent pattern of reduction in variability with increasing level of replication, for both point counts and transects, but with no appreciable change in precision of estimates beyond 10 to 15 replicates, in all species groups. Consequently, and because of the high variability inherent in fish density estimates, we recommend strongly that at least 10 replicates are used to quantify the species considered here, and would treat with caution studies where sample sizes were smaller. Given this result, and since point counts could be deployed in $\sim 70 \%$ of the time of transects, our results indicate that the point count is a more efficient method.

The variability in the density estimates of the UVC methods was generally very high, and data distributions were non-normal, thereby reducing the power of the analyses to detect significant differences. This variability reflected the highly contagious distributions of many of the species in relation to the feasible sizes of
UVC sampling units, a feature typical of reef fishes (Sale 1991, Williams 1991). With these sampling constraints, standard measures of precision (e.g. SE/mean ratios, coefficients of variation) have limited application. This problem has a significant bearing on power analyses: the calculations are not robust when using non-normally distributed data (Zar 1996). Therefore, the greater power obtained with point counts compared with the transects may not be real. The power calculations suggested that for both transects and point counts only fairly large differences in density (e.g. at least $50 \%$ ) will be detected with the replication levels typical of UVC surveys.

The effectiveness of a visual census method is likely to be closely related to the mobility and/or crypticity of the fish relative to the census area (Thresher \& Gunn 1986, Lincoln Smith 1989, Samoilys \& Carlos ${ }^{3}$, Watson et al. 1995), hence the breakdown of families into species groups based on their mobility for the data analyses in the present study. The varying mobilities of the different species were apparent in the responses of the species groups to different methods (e.g. census dimension). It is therefore important to define these behavioural attributes carefully prior to selecting a UVC method. In addition, we found temporal stratification in counting (see Methods) to be important if counting a range of species of varying mobilities and/or behaviours. Thus the more mobile (usually larger, and probably 'diver-shy') species, such as the serranids and lethrinids, should be counted first, followed by the more sedentary groups, such as the acanthurids and small scarids. Although stratification in counting is possible in both methods it is easier in point counts because the whole census area is visible to the observer throughout the count and therefore the observer is able to be more effective in targeting the mobile species first. It has been shown that trainee observers find a fixed census area less ambiguous (Samoilys et al. ${ }^{4}$ ). With strip transects the observer must continuously re-prioritise the observable fish as new sections of the transect are encountered. Thus, the observer looks ahead, counts the mobile species, then on reaching the area ahead counts the sedentary species, meanwhile counting the mobile species ahead, and so forth. With practice this is not difficult, and our results indicate that such counting is no less accurate than that by a stationary observer in a point count. The issue of counting a range of species simultaneously was investigated in some detail by Lincoln Smith (1989) who concluded accuracy was improved if species groups are counted separately using the most 
appropriate method for each group. Our results support this recommendation, though this has to be balanced against the extra cost (time) involved in deploying more than one method.

In summary, our results indicate that strip transects and stationary point counts are equally effective UVC methods for the groups of species we considered, though point counts are more efficient. We suggest the mobility and behaviour of the species being counted, which relate to variations in census dimensions and speed, are important considerations. Researchers who use UVC have probably now expended sufficient resources in refining the method, however, the power to detect changes in coral reef fish population densities is still low. This reflects the spatial distribution patterns of these fishes. We suggest future research should investigate the development of alternative methods based on spatial analyses of fish distribution patterns.

\section{Acknowledgements}

We thank Maciu Lagibalavu, Krishna Swamy, Apisai Sesewa, Eseroma Ledua, Edward Tesi and George Meden of the Fisheries Division of Fiji, and Lyle Squire (DPI Fisheries) and Allan Lisle (DPI Biometry) for their assistance in this work. We are grateful to Jim Higgs for assistance with bootstrapping and Dorothée Teboul for assistance with the figures. The study was funded by the Australian Centre for International Agricultural Research.

\section{References cited}

Allen, G.R. 1985. FAO species catalogue, Vol. 6. Snappers of the world. An annotated and illustrated catalogue of lutjanid species known to date. FAO Fish. Synopses 125. 208 pp.

Allen, G.R. 1987. Synopsis of the circumtropical fish genus Lutjanus (Lutjanidae). pp. 33-88. In: Polovina, J.J. and Ralston, S. (eds), Tropical Snappers and Groupers: Biology and Fisheries Management, Westview Press, London.

Allen, G.R. \& R. Swainston. 1988. The marine fishes of northwestern Australia. Western Australian Museum, Perth. 201 pp.

Andrew, N.L. \& B.D. Mapstone. 1987. Sampling and the description of spatial pattern in marine ecology. Oceanogr. Mar. Biol. Ann. Rev. 25: 39-90.

Bell, J.D., G.J.S. Craik, D.A. Pollard \& B.C. Russell. 1985. Estimating length frequency distributions of large reef fish underwater. Coral Reefs 4: 41-44.

Bellwood, D.R. \& A.C. Alcala. 1988. The effect of a minimum length specification on visual estimates of density and biomass of coral reef fishes. Coral Reefs 7: 23-27.
Bohnsack, J.A. \& S.P. Bannerot. 1986. A stationary visual census technique for quantitatively assessing community structure of coral reef fishes. NOAA Technical Report NMFS 41: 1-15.

Brock, R.E. 1982. A critique of the visual census method for assessing coral reef fish populations. Bull. Mar. Sci. 32: 269-276.

Bros, W.E. \& B.C. Cowell. 1987. A technique for optimizing sample size replication. J. Exp. Mar. Biol. Ecol. 114: 63-71.

Brown, I.W. 1993. Fish and fisheries of Queensland. pp. 20-26. In: Australian Bureau of Statistics (ed.), Queensland Year Book 1994, 52, Brisbane.

Carcasson, R.H. 1977. A field guide to the coral reef fishes of the Indian and west Pacific Oceans. Collins, London. 320 pp.

Carpenter, R.C. \& G.R. Allen. 1989. FAO species catalogue. Emperor fishes and large-eye breams of the world (family Lethrinidae). An annotated and illustrated catalogue of lethrinid species know to date. FAO Fish. Synopses, Rome 125 (9): 1-118.

Choat, J.H. \& J.E. Randall. 1986. A review of the parrotfishes family Scaridae of the Great Barrier Reef of Australia with description of a new species. Rec. Aust. Mus. 38: 175-228.

Efron, B. \& R.J. Tibshirani. 1993. An introduction to the bootstrap. Chapman \& Hall, New York. 436 pp.

English, S., C. Wilkinson \& V. Baker (eds). 1994. Survey manual for tropical marine resources. ASEAN-Australia Science Project, Australian Institute of Marine Science, Townsville. 368 pp.

Fischer, W. \& G. Bianchi. 1984. FAO species identification sheets for fishery purposes. Western Indian Ocean (Fishing Area 51), Vol 1-6, FAO, Rome.

Fowler, A.J. 1987. The development of sampling strategies for population studies of coral reef fishes. A case study. Coral Reefs 6: 49-58.

Grant, E.M. 1982. Guide to fishes, 5th edition. Dept. of Harbours \& Marine, Brisbane. 896 pp.

Green, R.H. 1979. Sampling design and statistical methods for environmental biologists. Wiley Interscience, New York. $257 \mathrm{pp}$.

Harmelin-Vivien, M.L., J.G. Harmelin, C. Chauvet, C. Duval, R. Galzin, P. Lejeune, G. Barnabe, F. Blanc, R. Ghevalier, J. Duclerc \& G. Lasserre . 1985. Evaluation visuelle des peuplements et populations de poissons: methodes et problemes. Review of Ecology (Terre Vie) 40: 468-539.

Jennings, S. \& N.V.C. Polunin. 1996. Effects of fishing effort and catch rate upon the structure and biomass of Fijian reef fish communities. J. Appl. Ecol. 33: 400-412.

Jennings, S., D.P. Boulle \& N.V.C. Polunin. 1996. Habitat correlates of the distribution and biomass of Seychelles' reef fishes. Env. Biol. Fish. 46: 15-52.

Kailola, P.J., M.J. Williams, P.C. Steward, R.E. Reichelt, A. McNee \& C. Grieve. 1993. Australian fisheries resources. Bureau of Resource Sciences, Commonwealth of Australia, Canberra. 422 pp.

Kulbicki, M. 1988. Correlation between catch data from bottom longlines and fish censuses in the SW lagoon of New Caledonia. Proc. 6th Int. Coral Reef Symp. 2: 305-312.

Lincoln Smith, M.P. 1988. Effects of observer swimming speed on sample counts of temperate rocky reef fish assemblages. Mar. Ecol. Prog. Ser. 43: 223-231. 
Lincoln Smith, M.P. 1989. Improving multispecies rocky reef fish census by counting different groups of species using different procedures. Env. Biol. Fish. 26: 29-37.

Masuda, H., K. Amaoka, C. Araga, T. Uyeno \& T. Yoshino (ed). 1984. The fishes of the Japanese Archipelago. Tokai University Press, Tokyo. 437 pp.

McManus, J.W., C.L. Nanola, R.B. Reyes \& K.N. Kesner. 1992. Resource ecology of the Bolinao coral reef system. ICLARM Stud. REV. 22, ICLARM, Manila. 117 pp.

Myers, R.F. 1989. Micronesian reef fishes. A practical guide to the identification of the coral reef fishes of the tropical Central and Western Pacific. Coral Graphics, Guam. 298 pp.

Polunin, N.V.C. \& C.M. Roberts. 1993. Greater biomass and value of target coral-reef fishes in two small Caribbean marine reserves. Mar. Ecol. Prog. Ser. 100: 167-176.

Randall, J.E. 1983. Red Sea reef fishes. IMMEL Press, London. $192 \mathrm{pp}$

Randall, J.E. \& A. Ben-Tuvia. 1983. A review of the groupers (Pisces: Serranidae: Epinephelinae) of the Red Sea, with description of a new species of Cephalopholis. Bull. Mar. Sci. 332: 373-426.

Randall, J.E. \& D.F. Hoese. 1986. Revision of the groupers of the Indo-Pacific genus Plectropomus (Perciformes: Serranidae) Indo-Pacific Fishes No. 13, P. Bernice Bishop Museum, Honolulu. 31 pp.

Randall, J.E. 1987. A preliminary synopsis of the groupers (Perciformes: Serranidae: Epinephelinae) of the Indo-Pacific region. pp. 89-188. In: J.J. Polovina, J.J. and Ralston, S. (eds), Tropical Snappers and Groupers: Biology and Fisheries Management, Westview Press, Boulder.

Russ, G.R. 1985. Effects of protective management on coral reef fishes in the central Philippines. Proceedings 5th International Coral Reef Symposium 4: 219-224.

Sale, P.F. 1991. Reef fish communities: open nonequilibrial systems. pp. 564-596. In: P.F. Sale (ed.), The Ecology of Fishes on Coral Reefs, Academic Press, San Diego.

Sale, P.F. \& B.J. Sharp. 1983. Correction of bias in visual transect censuses of coral reef fishes. Coral Reefs 2: 37-42.

Samoilys, M.A. 1988. Abundance and species richness of coral reef fish on the Kenyan coast: the effects of protective management and fishing. Proc. 6th Int. Coral Reef Symp. 2: 261-266.

Samoilys, M.A. 1992. Review of the underwater visual census method developed by the DPI/ACIAR project: visual assessment of reef fish stocks. Conference and Workshop Series QC92006, Department of Primary Industries, Brisbane. 55 pp.

Samoilys, M.A. 1997. Underwater visual census surveys. pp. 16-29. In: M.A. Samoilys (ed.) Manual for Assessing Fish Stocks on Pacific Coral Reefs, Queensland Department of Primary Industries, Townsville.

Smith, M.M. \& P.C. Heemstra (eds). 1986. Smith's sea fishes. Springer-Verlag, New York. 1047 pp.

Southwood, T.R.E. 1978. Ecological methods, with particular reference to the study of insect populations, 2nd edition. Chapman \& Hall, London. 524 pp.

Thresher, R.E. \& J.S. Gunn. 1986. Comparative analysis of visual census techniques for highly mobile, reef-associated piscivores (Carangidae). Env. Biol. Fish. 172: 93-116.

Trainor, N. 1991. Commercial line fishing. The Queensland Fisherman, March 1991: 17-25.

Underwood, A.J. 1981. Techniques of analysis of variance in experimental marine biology and ecology. Oceanogr. Mar. Biol. Ann. Rev. 19: 513-605.

Watson, M. \& R.F.G. Ormond. 1994. Effect of an artisanal fishery on the fish and urchin populations of a Kenyan coral reef. Mar. Ecol. Prog. Ser. 109: 115-129.

Watson, R.A., G.M. Carlos \& M.A. Samoilys. 1995. Bias introduced by the non-random movement of fish in visual transect surveys. Ecol. Modelling 77: 205-214.

Williams, D.McB. 1991. Patterns and processes in the distribution of coral reef fishes. pp. 437-473. In: Sale, P.F. (ed.), The Ecology of Fishes on Coral Reefs, Academic Press, San Diego.

Winer, B.J., D.R. Brown \& K.M. Michels. 1991. Statistical principles in experimental design, 3rd ed. McGraw-Hill, New York. $1057 \mathrm{pp}$.

Zar, J.H. 1996. Biostatistical analysis, 3rd ed. Prentice-Hall International, Englewood Cliffs. 662 pp. 